\title{
ACIDENTES COM PRODUTOS QUÍMICOS PERIGOSOS NO ESTADO DE GOIÁS
}

\author{
Wanderley Valério de Oliveira ${ }^{1}$ \\ Sandra Regina Longhin ${ }^{2}$ \\ Cleonice Rocha ${ }^{3}$
}

\section{RESUMO}

Ocorrências envolvendo produtos químicos perigosos vêm aumentando em todo o país e com isso surge a preocupação em se conhecer os principais produtos envolvidos nestes acidentes. A pesquisa aqui apresentadas consta de uma compilação de acidentes relacionados a produtos químicos perigosos no estado de Goiás, entre 2007 e 2010. O objetivo da mesma foi o de avaliar as causas, a evolução, estabelecendo relações entre ambas e com o transporte. Para tanto, contou-se com o apoio de 39 quartéis do Corpo de Bombeiros Militar em todo território do estado de Goiás, de empresas que fazem o manejo de produtos perigosos, órgãos de fiscalização ambiental e de trânsito, os quais contribuíram também para a avaliação das possíveis causas ou correlações com os acidentes. Os materiais perigosos com maior número de ocorrência em todos os anos compilados foram: gás liquefeito de petróleo, óleo diesel, álcool anidro, gasolina e gás amônia. A comparação da evolução dos acidentes com os referidos produtos e a quantidade de produção, vendas e inspeções permitiu estabelecer as possíveis causas dos mesmos. A pesquisa mostrou também que a estrutura de informatização das instituições que faziam o atendimento dos acidentes no início do período pesquisado não cobria todo o espaço territorial de Goiás, e que o avanço nesta área levou ao aumento na quantidade de ocorrências registradas, o que tornou o sistema eficiente. Deste modo, conclui-se que quanto mais confiáveis as informações sobre os acidentes, mais evidentes tornam-se as causas dos mesmos, contribuindo assim, para a minimização do problema com um gestão logística eficiente.

Palavras-chave: Produtos Químicos Perigosos; Acidentes com Produtos Químicos; Transporte Produtos Químicos Perigosos.

\footnotetext{
${ }^{1}$ Oficial do Corpo de Bombeiros Militar de Goiás, Mestre em Química pela PUC-GO. Email: quim.msc@gmail.com

${ }^{2}$ Professora Doutora PUC - GO ECEC/MCAS e do Instituto Federal de Educação, Ciências e Tecnologia de Goiás. Email:srlpucgoias@gmail.com

${ }^{3}$ Professora Doutora PUC - GO ECEC/Programa de Mestrado em Ecologia e Produção Sustentável. Email:rcleonice@gmail.com
} 


\title{
ACCIDENTS WITH HAZARDOUS CHEMICAL PRODUCTS IN GOIÁS - BR
}

\begin{abstract}
Events involving hazardous chemicals are increasing all over the country and with that comes the concern to know the main products involved in these accidents. In this work is have made compilation of accidents related to dangerous products in the state of Goiás from 2007 to 2010 to evaluate its evolution, establish relationships with their possible causes on transport of them. For this propose we had support from 39 fireman of the Fire Brigade on territory of the Goiás state, companies that make the handling of hazardous materials, environmental and transit monitoring agencies, in order to find the assessment the possible causes or correlations with the accident. Hazardous materials with the most occurring number in all compiled years were liquefied petroleum gas, diesel oil, anhydrous alcohol, gasoline and ammonia gas. Comparing the evolution of accidents involving such products and the quantity of production, sales and inspections allowed us to establish its possible causes. On the other hand, it is not always managed to link the accident with some cause and this can be caused by the deficiency in information technology service of the institutions. Thus, it is concluded that the closer to reality is the information on accidents, more evident become its causes, thus contributing to minimization problem and allocating resources.
\end{abstract}

Keywords: Hazardous Products; Accidents; Transport Hazardous Products.

Artigo recebido em 18/07/16 e Aceito em 12/02/17. 


\section{INTRODUÇÃO}

O Brasil é um país de dimensões continentais, recortado por rodovias, sendo o transporte rodoviário a base para o deslocamento de cargas como produtos industrializados e matérias primas. $O$ desenvolvimento das regiões Norte (N), Nordeste (NE), Centro-oeste (CO) e do Distrito Federal (DF) trouxe a necessidade de consumo de produtos químicos produzidos nas regiões Sul (S) e Sudeste (SE) do país. A partir desta constatação, observou-se também o crescimento vertiginoso do transporte de produtos químicos nas rodovias que cortam o Estado de Goiás (GO) e, com isto, o aumento no número de acidentes nestas rodovias.

O Perfil Nacional de acidentes envolvendo produtos químicos perigosos (MMA, 2016) apresenta dados do período de 2006 a 2010, onde se observa o número significativo de acidentes ocorridos com óleo diesel, gasolina, etanol e gás liquefeito de petróleo (GLP). Os dados apontam os eventos que ocorrem com maior frequência, e estes estão associados ao transporte rodoviário dessas substâncias químicas, classificadas como perigosas.

Os acidentes que envolvem o transporte rodoviário de produtos químicos perigosos (PP) podem atingir a população sendo uma ameaça séria devido aos graves riscos de contaminação (BECKER; PITT; CLARK, 2000). Além de colocar em risco a segurança e a saúde das pessoas, o meio ambiente fica sujeito a essa situação devido a possibilidade dos PP atingirem os cursos d'água, contaminarem o solo, o ar atmosférico e até mesmo o lençol freático por infiltração (PEDRO, 2006).

O estado de Goiás possui uma particularidade, é o centro de recebimento e distribuição de combustível energético e amônia para toda a região $\mathrm{CO}, \mathrm{N}, \mathrm{NE}$ e para o DF sendo também, atualmente, um dos maiores produtores de etanol no Brasil. 
A condição estratégica do estado de Goiás, confluências das regiões $\mathrm{N}, \mathrm{NE}$, do DF e S e SE, leva a um consumo significativo de combustível o que expõe o estado ao risco eminente de acidentes nas rodovias que o cortam. $O$ desenvolvimento acelerado da agroindústria, da indústria fabril (FIEG/DEC, 2010) e da área de tecnológica (SEBRAE, S/D) dos últimos anos coloca o estado de Goiás em condição de alerta, pois grande parte de sua produção utiliza PP para suprir as necessidades econômicas e sociais advindas deste crescimento, necessitando de um controle e/ou acompanhamento rigoroso quanto ao consumo e manejo desses produtos.

Em caso de acidentes que envolvem PP, informações como os riscos dos reagentes químicos, o local do sinistro, o produto específico envolvido e sua quantidade (quando possível identificar), se ocorreram no modal de transporte rodoviário, se houve contaminação de bacias hidrográficas, explosão, vazamento, incêndio dentre outras, podem colaborar com a minimização do impacto econômico, social e ambiental causado pelos mesmos.

A análise histórica dos acidentes ocorridos também favorece o estudo do risco, a vulnerabilidade, a ameaça e a periculosidade dos PP. O registro dos acidentes se faz um instrumento pertinente para futuros planejamentos sóciopolíticos, atuações do poder público na tomada de decisões e direcionamento de recursos, criação de programas para o gerenciamento dos riscos, além de contribuir com várias informações e respostas para os pesquisadores no desenvolvimento científico.

Devido ao exposto acimo, esta pesquisa teve como objetivo analisar os acidentes com produtos químicos perigosos, ocorridos no estado de Goiás, no período de 2007 a 2010, registrado pelo Corpo de Bombeiros Militar do Estado de Goiás (CBMGO) avaliando o quantitativo, o tipo de produto envolvido, as causas e evolução no período. 
Revista Científica do Corpo de Bombeiros Militar de Pernambuco

Seção 1 - Artigos Técnico Científicos

Artigo publicado no Vol.03 №06 - Edição de JAN a JUN 2017 - ISSN 2359-4829

Versão on-line disponível em: http://www.revistaflammae.com

\section{METODOLOGIA}

A pesquisa foi realizada de forma quantitativa, a partir dos dados registrados das ocorrências, no período de 2007 a 2010, pelo CBMGO, com a devida autorização do órgão.

As informações disponibilizadas por 39 (trinta e nove) Quartéis do CBMGO possibilitaram uma visão geral das ocorrências em todo o estado de Goiás. Estes dados encontram-se registrados como dados reais na rede da Secretaria da Segurança Pública e Administração Penitenciária de Goiás (SSPAPGO).

A partir dos dados obtidos, analisou-se a correlação das possíveis causas dos acidentes com os veículos envolvidos, o estado das rodovias e o tipo de PP (derivados do petróleo, etanol, amônia entre outros).

A figura 1 a seguir apresenta mapas de Goiás onde podemos observar claramente a confluências das rodovias para a região da grande Goiânia bem como a conexão com as demais regiões do país e os outros estados que compõem a região $\mathrm{CO}$.
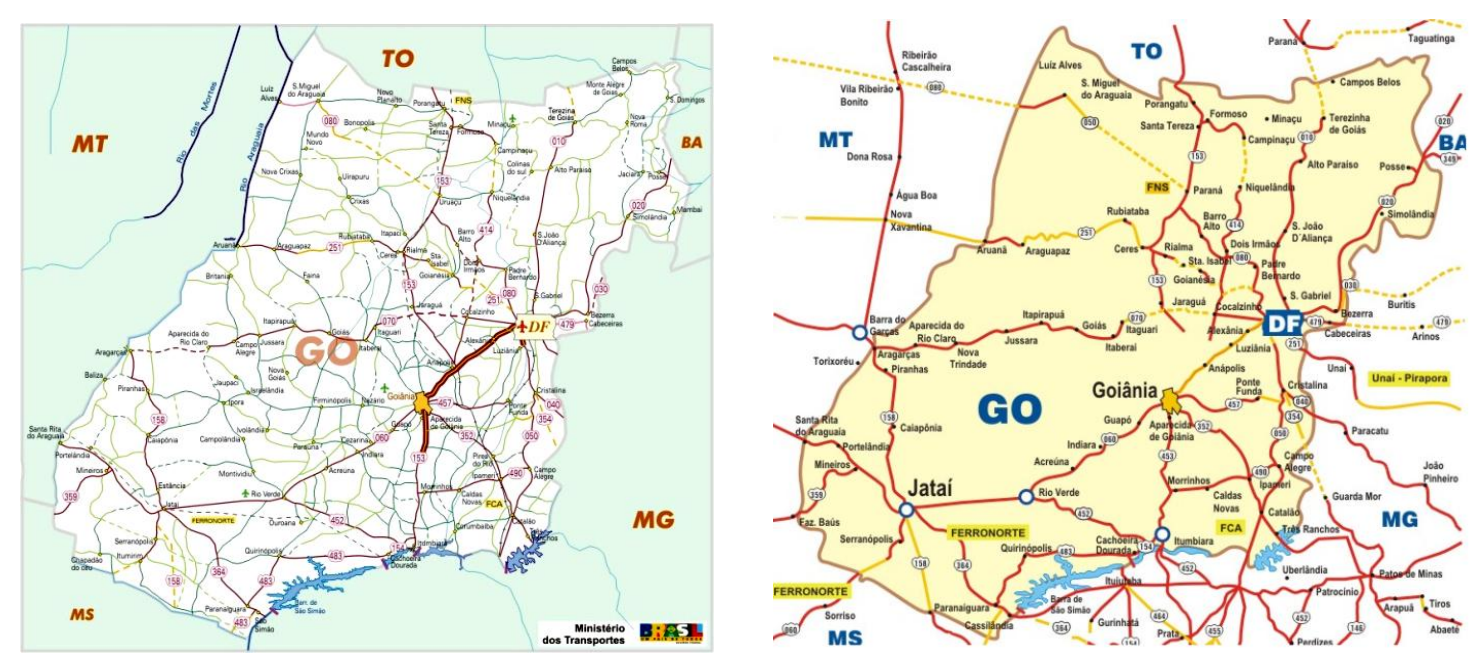

Figura 1: Mapa de Goiás: (A) Rodoviário, hidroviário e aeroportuário oficial, (B) rodoviário logístico.

Fonte: Mapa (A) http://www.zonu.com/brazil_maps/Goias_State_Federal_Highway_Map_Brazil_2.htm Mapa (B) http://logisticagoiana.blogspot.com.br/2012_01_01_archive.htm. Acesso em 30/03/2016 


\section{RESULTADOS E DISCUSSÃO}

A tendência de crescimento de acidentes com produtos químicos perigosos, observada para o Estado de Goiás no período de 2007 a 2010, coincide com o acelerado crescimento agroindustrial, fabril (FIEG/DEC, 2010) e tecnológico (SEBRAE, S/D), pois este gera um aumento na demanda de produtos como combustíveis e gases refrigerantes tóxicos.

$\mathrm{O}$ aquecimento da economia leva a um aumento na demanda por PP, o que requer medidas de segurança e fiscalização que acompanhem o transporte e manejo dos PP.

Entre as causas do crescimento de ocorrências de acidentes com PP no estado de Goiás pode-se destacar o aumento da frota veicular (DETRAN, 2010b) e também as condições físicas das rodovias goianas (CNT, 2010), onde observamos falta de manutenção, ausência de equipamentos de segurança disponíveis ao longo das mesmas, forma inadequada de armazenamento do PP durante as paradas de descanso dos motoristas além da falta de preparo dos profissionais que atuam nesta área, como por exemplo, os frentistas de postos de combustíveis.

De acordo com o Departamento Estadual de Trânsito (DETRAN, 2010b) em Goiás, no período de 2007 até agosto do ano de 2010 houve um aumento quantitativo da frota de veículos no estado de Goiás. Em 2007 foram 1875388 veículos no sistema viário, 2008 aumentou de 11,78\% em relação a 2007 com 2096488 veículos, 2009 aumento de 8,92\% em relação a 2008 (2 302 048) e até agosto do ano de 2010 houve aumento de 5,82\% (2 444 491) de veículos registrados em relação ao ano de 2009.

No mesmo departamento (DETRAN, 2010a), foram sistematizadas as estatísticas sobre o aumento do número de acidentes de trânsito em todo estado de Goiás no período de 2007 ao ano de 2010, incluindo os de acidentes envolvendo PP. 
O aumento da frota de veículos nas malhas viárias goianas é um indicador para o crescimento de consumo e comercialização de combustível logo do transporte de PP, o que pode acarretar maior probabilidade de acidentes, produzindo danos materiais, prejuízo econômico, perda de vidas humanas e problemas ambientais.

Os dados obtidos na pesquisa mostraram a evolução dos acidentes envolvendo o transporte e armazenamento de produtos químicos perigosos em Goiás, os registros passaram de 28 em 2007, para 30 em 2008, 57 em 2009 e 101 em 2010, o que significou um crescimento de $360 \%$ no período avaliado.

O panorama no Brasil pode ser observado como um todo por meio dos dados disponibilizados pelo do Instituto Brasileiro de Meio Ambiente e Recursos Naturais Renováveis (IBAMA, 2010), que revelam um crescimento numa razão de $42,7 \%$ dos acidentes envolvendo PP entre os anos de 2006 e 2010, o que coloca Goiás em primeiro lugar quando se avalia a razão de crescimento frente aos demais estados $(360 \%)$. Este resultado pode estar relacionado não somente com o aumento de casos como também com a frequência do registro dos mesmos em função do maior contingente de profissionais trabalhando na área (Bombeiros Militares e Policiais Rodoviários), do uso de novas tecnologias de comunicação e com um melhor aparelhamento tecnológico do Estado que possibilita o registro das informações.

Segundo os dados do IBAMA, no Brasil acidentes ambientais com PP, mostram as rodovias como local de maior incidência, o que se justifica em virtude da predominância do modal rodoviário na matriz de transporte brasileiro (IBAMA, 2010). No estado de São Paulo no período 2008/2009 o transporte rodoviário também se destacou como o principal responsável pelos acidentes com PP (CETESB, 2009).

Em Goiás, de janeiro de 2007 até 2010, 40,74\% das ocorrências compiladas de PP estão relacionadas ao transporte rodoviário e 59,26\% ao armazenamento. Mesmo as comunidades distantes da produção industrial, da 
movimentação ou instalações de armazenamentos, ficam sujeitas aos riscos de acidentes e de contaminação associados ao transporte (BECKER; PITT; CLARK, 2000) devido a dinâmica do deslocamento no transporte do produto perigoso, podendo ser em qualquer lugar, e pelo poder de extrapolar os limites espaciais e temporais.

De acordo com as pesquisas da Confederação Nacional de Transportes (CNT, 2010) as condições gerais das rodovias goianas são consideradas como ruins e péssimas, com problemas de pavimentação, sinalização e/ou geometria viária. Diante disso, em 2007 o desgaste atingiu (76,6\%), 2009 (72\%) e 2010 (65,7\%) destas vias, que são qualificadas entre regular, ruim e péssima. A rodovia BR-158 (Jataí/Piranhas) e a GO-174 (Rio Verde/Iporá) estão entre as dez piores do Brasil. Apresentando também alguns defeitos consideráveis, como, buracos, ondulações, deficiências nas sinalizações, dentre outros.

Apesar do estado das rodovias goianas serem um fator determinante para a ocorrência de acidentes, se verifica nos dados obtidos na pesquisa que as ocorrências envolvendo o transporte terrestre de PP são registradas em vias com perfeitas condições de uso, colocando o condutor do veículo na condição de responsável, pois o cansaço e a ingestão de bebidas alcoólicas são considerados de uma forma geral, como os fatores responsáveis pela maioria dos acidentes registrados no país, como divulgado constantemente pela mídia.

Os PP envolvidos nos acidentes/incidentes de 2007 até o ano de 2010, de acordo com os dados obtidos, indicaram os combustíveis e derivados de petróleo como os de maior incidência. Acidentes com a substância química amônia $\left(\mathrm{NH}_{3}(\mathrm{~g})\right)$, utilizada como gás refrigerante pela agroindústria foi contatado em todo período pesquisado.

Os acidentes com amônia são preocupantes pelo fato de que esta substância é transportada no estado líquido (amônia Industrial), porém nas condições ambientais (CNTP) se encontrada no estado gasoso, o que facilita a 
Revista Científica do Corpo de Bombeiros Militar de Pernambuco

Seção 1 - Artigos Técnico Científicos

Artigo publicado no Vol.03 №06 - Edição de JAN a JUN 2017 - ISSN 2359-4829

Versão on-line disponível em: http://www.revistaflammae.com

sua dispersão na atmosfera. A amônia é tóxica se inalada, provoca queimadura severa à pele com dor, formação de bolhas e descamação da pele, o contato do gás liquefeito pode causar "queimaduras pelo frio" (frostbite), lesões oculares graves/irritação ocular com lacrimejamento, dor, edema palpebral, ulceração da córnea e atrofia da íris podendo levar à cegueira, pode provocar sintomas alérgicos ou asmáticos e dificuldades respiratórias com tosse e falta de ar sendo para o ambiente considerado um gás muito tóxico para a vida aquática, com baixa mobilidade sendo fortemente adsorvido pelo solo entre outros efeitos adversos (FISPQ - Amônia Industrial, 2016 e MTE, 2004).

Os dados obtidos para PP indicam a maior incidência de ocorrências no ano de 2010, sendo que sua distribuição encontra-se apresentado na figura 2 a seguir.

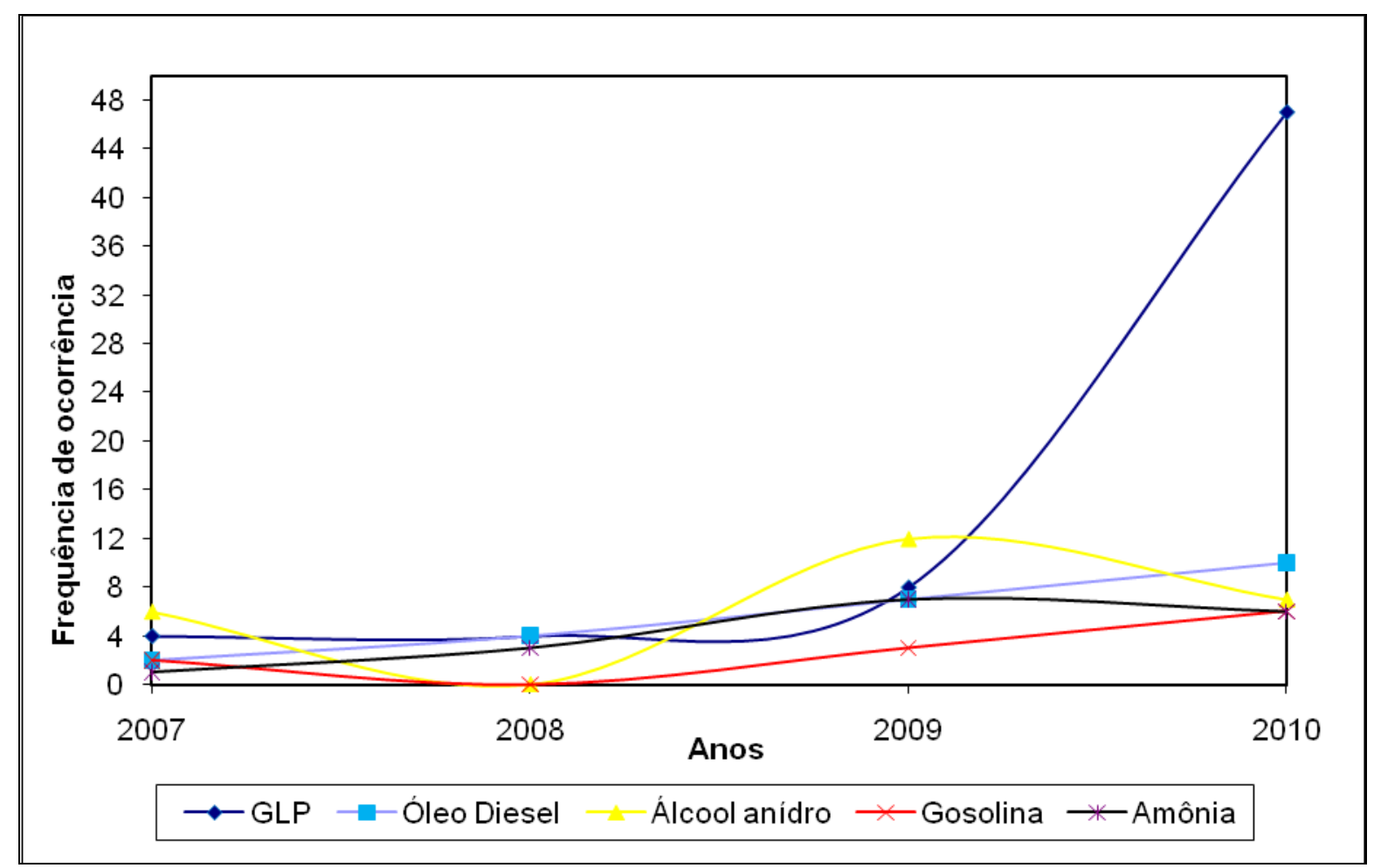

Figura 2 - Principais compostos registrados nos acidentes com produtos perigosos. Fonte: SIAE/COB, 2010. 
Revista Científica do Corpo de Bombeiros Militar de Pernambuco

Seção 1 - Artigos Técnico Científicos

Artigo publicado no Vol.03 №06 - Edição de JAN a JUN 2017 - ISSN 2359-4829

Versão on-line disponível em: http://www.revistaflammae.com

Os dados mostram que o GLP apresentou um crescimento significativo, de 04 para 47 unidades, seguido do óleo diesel que passou de 02 para 10 no período de 2007 a 2010.

O Ministério do Meio Ambiente (MMA, 2009) destaca que os principais agentes químicos poluentes que causam danos ao meio ambiente e que expõem as pessoas a doenças são os derivados de petróleo. Considerando-se que o maior número de ocorrências envolveu os derivados de petróleo como o GLP e óleo diesel são necessários mais estudos que permitam uma avaliação casos a caso.

A partir dos dados obtidos, foi possível centrar o foco da pesquisa na análise nos PP descritos a seguir.

\subsection{Gás liquefeito de petróleo (GLP)}

O número de inspeções a locais de venda e acidentes associados a comercialização de gás liquefeito de petróleo no período de 2007 a 2010 encontra-se apresentado no quadro 1.

Quadro 1 - Número de acidentes, inspeções e venda de gás liquefeito de petróleo nos anos de 2007 a 2010.

\begin{tabular}{|c|c|c|c|c|}
\hline Período & $\begin{array}{c}\text { Número de } \\
\text { ocorrências }\end{array}$ & $\begin{array}{c}\text { Crescimento } \\
(\mathbf{\%})\end{array}$ & $\begin{array}{c}\text { Venda } \\
\left(\mathbf{x}^{\mathbf{3}} \mathbf{~ m}^{\mathbf{3}} \mathbf{)}\right.\end{array}$ & $\begin{array}{c}\text { Número de } \\
\text { inspeções }\end{array}$ \\
\hline 2007 & 04 & - & 460,48 & DNE \\
\hline 2008 & 04 & 0 & 470,27 & DNE \\
\hline 2009 & 08 & 200 & 462,30 & 8549 \\
\hline 2010 & 47 & 487,5 & DNE & 13563 \\
\hline
\end{tabular}

DNE = Dado não encontrado

Fonte: SIAE/COB, 2010; SIAPI, 2011; ANP, 2010.

No biênio 2007 - 2008 observa-se 04 acidentes, com a venda praticamente constante. Em 2009 a quantidade de ocorrências dobrou, a venda de GLP praticamente se manteve igual ao do período anterior e as inspeções compiladas foram de 8549. O número de acidentes entre os anos de 2009 e 2010 aumentou 487,5\% mas a quantidade de inspeções cresceu aproximadamente de $59 \%$, desta forma a evolução pode ser entendida como 
resultado de uma maior frequência da vistoria e portanto do registro das ocorrências. Em 2010 a informatização da Segurança Pública no estado de Goiás, e portanto do Corpo de Bombeiros Militar (CBMGO), foi integrada pelo Sistema Integrado de Análises de Projetos e Inspeções (SIAPI), assim a eficiência de compilação das inspeções solicitadas pelas empresas e acidentes foi maior (SIAPI, 2011).

A eficácia das ações preventivas e de registro de acidentes através das inspeções também foi melhorada devido ao convênio do CBMGO com Agência Nacional do Petróleo, Gás Natural e Biocombustíveis (ANP) efetivada a partir de 2008.

Os registras do SIAPI indicam que a maioria dos acidentes com GLP ocorreram no procedimento de armazenamento domiciliar (residência $\mathrm{e}$ apartamento) e em estabelecimentos comerciais tais como restaurantes, bares e indústrias (SIAE/COB, 2010).

\section{2 Óleo diesel}

O consumo do óleo diesel é maior se comparado com o da gasolina, devido ao abastecimento, principalmente de maquinário agropecuário como caminhões, colheitadeiras e tratores, pois esses veículos detêm um maior poder de consumo de combustível por litro, e são utilizados em atividades agrícolas cujo consumo aumenta em época de safras (TRANSPETRO, 2011).

O número de acidentes relativos à comercialização de óleo diesel no período de 2007 a 2010 é apresentado no quadro 2 . 
Revista Científica do Corpo de Bombeiros Militar de Pernambuco

Seção 1 - Artigos Técnico Científicos

Artigo publicado no Vol.03 №06 - Edição de JAN a JUN 2017 - ISSN 2359-4829

Versão on-line disponível em: http://www.revistaflammae.com

Quadro 2 - Número de ocorrências e volume de venda de óleo diesel nos anos de 2007 a 2010

\begin{tabular}{|c|c|c|c|}
\hline Período & $\begin{array}{c}\text { Número de } \\
\text { ocorrências }\end{array}$ & $\begin{array}{c}\text { Crescimento } \\
(\%)\end{array}$ & $\begin{array}{c}\text { Venda } \\
\left(\mathbf{m}^{3}\right)\end{array}$ \\
\hline 2007 & 2 & - & 1715460 \\
\hline 2008 & 4 & 200 & 2184910 \\
\hline 2009 & 7 & 175 & 2168352 \\
\hline 2010 & 10 & 142 & 2486798 \\
\hline
\end{tabular}

Fonte: SIAE/COB, 2010; TRANSPETRO (2011).

Um dado importante é que o óleo diesel fracionado da Refinaria Paulínia em São Paulo é transportado para o estado de Goiás via dutos.

Os dados indicam que no período estudado, o número de ocorrência de acidentes com óleo diesel dobrou e sua venda cresceu aproximadamente $27,4 \%$. No ano de 2008 e 2009 a quantidade de acidentes aumentou, porém a venda do combustível praticamente se manteve. Entre o ano de 2009 e 2010 o número de acidentes e venda do óleo diesel cresceu $142 \%$, indicando a possibilidade de influência da comercialização no número de acidentes.

De acordo o banco de dados SIAE/COB, não houve registro de acidente envolvendo o transporte por meio de duto. Quando o óleo diesel chega aos terminais da TRANSPETRO em Senador Canedo, o transporte passa a ser no modal rodoviário e o combustível é distribuído para todo estado, assim a maioria dos acidentes envolvendo o óleo diesel é devido ao transporte rodoviário (SIAE/COB, 2010).

\subsection{Etanol}

Segundo a União da Indústria de Cana de Açúcar (UNICA, 2008), o Brasil é o maior produtor mundial de cana de açúcar. O estado de Goiás ocupa a $4^{\circ}$ posição no ranking dos estados que mais produzem esta cultura (CONAB, 2010).

O quadro 3 apresenta dados da safra de 2007 a 2010 destacando o crescimento industrial na área. 
Revista Científica do Corpo de Bombeiros Militar de Pernambuco

Seção 1 - Artigos Técnico Científicos

Artigo publicado no Vol.03 №06 - Edição de JAN a JUN 2017 - ISSN 2359-4829

Versão on-line disponível em: http://www.revistaflammae.com

Quadro 3 - Relação de usinas de álcool, produção de cana de açúcar e etanol no período de 2007 a 2010.

\begin{tabular}{|c|c|c|c|}
\hline Período & $\begin{array}{c}\text { Número de } \\
\text { usinas }\end{array}$ & $\begin{array}{c}\text { Produção de } \\
\text { cana } \\
\text { (mil toneladas) }\end{array}$ & $\begin{array}{c}\text { Produção de } \\
\text { álcool } \\
\text { (mil litros) }\end{array}$ \\
\hline $2007 / 2008$ & 18 & $23.137,4$ & $1.167 .028,1$ \\
\hline $2008 / 2009$ & 26 & $29.645,2$ & $1.758 .627,1$ \\
\hline $2009 / 2010$ & 33 & $44.491,9$ & $2.368 .080,5$ \\
\hline
\end{tabular}

Fonte: CONAB, 2009; CONAB 2007 e CONAB 2011.

Segundo a Agência Nacional do Petróleo (ANP) as vendas registradas de etanol em 2009 cresceram 24\% quando comparado ao ano de 2008, em função das vendas de veículos flex fuel (ANP, 2010).

$O$ aumento da quantidade de usinas, produção da cana de açúcar e do etanol no estado de Goiás não influenciou no número de ocorrências de acidentes, pois apesar da produção ter aumentado o número de acidentes variou de 06 em 2007, zero em 2008, 12 em 2009 e 07 em 2010.

A maioria dos acidentes envolvendo o combustível etanol ocorreu em rodovias e não nas usinas, sendo que a utilização do modal rodoviário para transportar esse produto, ligado ao aumento da frota veicular em circulação (DETRAN, 2010b) bem como o estado das rodovias (CNT, 2010) pode ser considerado como responsável.

\subsection{Gasolina}

O número de ocorrências relacionado à venda da gasolina no período de 2007 a 2010 está apresentado no quadro 4..

Quadro 4 - Número de ocorrências e venda de gasolina nos anos de 2007 a 2010

\begin{tabular}{|c|c|c|c|}
\hline Período & $\begin{array}{c}\text { Número de } \\
\text { ocorrências }\end{array}$ & $\begin{array}{c}\text { Crescimento } \\
(\mathbf{\%})\end{array}$ & $\begin{array}{c}\text { Venda } \\
\left(\mathbf{m}^{\mathbf{3}} \mathbf{)}\right.\end{array}$ \\
\hline 2007 & 2 & - & 665.083 \\
\hline 2008 & 0 & -200 & 698.914 \\
\hline 2009 & 3 & 300 & 729.002 \\
\hline 2010 & 6 & 200 & 823.031 \\
\hline
\end{tabular}

Fonte: SIAE/COB, 2010; TRANSPETRO 2011. 
Revista Científica do Corpo de Bombeiros Militar de Pernambuco

Seção 1 - Artigos Técnico Científicos

Artigo publicado no Vol.03 №06 - Edição de JAN a JUN 2017 - ISSN 2359-4829

Versão on-line disponível em: http://www.revistaflammae.com

Entre o ano de 2007 e 2008 (TRANSPETRO, 2011), ocorreu um pequeno aumento de venda da gasolina que não foi acompanhada pelo número de acidentes (quadro 3 ), sendo que as ocorrências triplicaram no período estudado.

A gasolina destilada na Refinaria Paulínia em São Paulo é transportada e vendida no estado de Goiás através de dutos de 20 polegadas de diâmetro (TRANSPETRO, 2011).

No período pesquisado, de acordo com o SIAE/COB (2010), foi registrado apenas um acidente envolvendo o transporte através de duto. Quando o combustível chega na TRANSPETRO, o transporte passa a ser rodoviário para a distribuição do combustível em todo estado, isto explica porque a maioria dos acidentes envolvendo a gasolina está vinculado ao transporte rodoviário. Logo as possíveis causas de acidentes seguem a mesma análise do PP etanol.

\subsection{Amônia}

O número de ocorrência relacionado à amônia no período de 2007 a 2010 é apresentado no quadro 5.

Quadro 5- Número de ocorrências e vendas da amônia nos anos de 2007 a 2010

\begin{tabular}{|c|c|c|c|}
\hline Período & $\begin{array}{c}\text { Número de } \\
\text { ocorrências }\end{array}$ & $\begin{array}{c}\text { Crescimento } \\
(\%)\end{array}$ & $\begin{array}{c}\text { Venda } \\
\text { (Kg) }\end{array}$ \\
\hline 2007 & 1 & - & 275.000 \\
\hline 2008 & 3 & 300 & 340.540 \\
\hline 2009 & 7 & 233 & 237.500 \\
\hline 2010 & 6 & -14 & 225.080 \\
\hline
\end{tabular}

Fonte: SIAE/COB, 2010; AMONID, 2011

De acordo com dados da empresa Amônea Produtos Químicos Ltda em Senador Canedo, a única revendedora de amônia lotada no estado de 
Revista Científica do Corpo de Bombeiros Militar de Pernambuco

Seção 1 - Artigos Técnico Científicos

Artigo publicado no Vol.03 №06 - Edição de JAN a JUN 2017 - ISSN 2359-4829

Versão on-line disponível em: http://www.revistaflammae.com

Goiás, os principais consumidores de amônia são as indústrias de bebidas, fábricas de gelo, frigoríficos e laticínios (AMONID, 2011).

No ano de 2009 e 2010 o número de ocorrência e venda da amônia diminuíram, pois vários frigoríficos e laticínios encerram suas atividades no estado.

Estes resultados mostram que não existe relação entre venda $e$ número de ocorrência de acidentes com gás amônia no estado de Goiás. A amônia utilizada em empresas de refrigeração é acumulada nos cilindros sob pressão e apresenta poucas perdas, o que se observa a diferença desse gás entre o GLP, etanol, gasolina e óleo diesel, que são consumidos pela combustão ou vaporização nos acidentes.

De acordo com o SIAE/COB, os acidentes compilados aconteceram no local de armazenamento, portanto as possíveis causas são devido à falta de informações e capacitação dos responsáveis pelo produto, falhas dos equipamentos, falta de manutenção nos aparelhos e danos nas tubulações em que o gás é armazenado.

\section{CONCLUSÕES}

Os resultados da pesquisa apontam para um aumento de cerca de 40,74\% nos acidentes estão relacionados ao transporte rodoviário no estado de Goiás sendo que uma das possíveis causas o estado de conservação em que se encontram as rodovias, entre as piores vias do Brasil, como divulgado recentemente pela imprensa no Jornal HORA 1, do portal g1.globo.com, em 22/01/2016.

Outros fatores também devem ser considerados como, por exemplo, a falta de capacitação dos motoristas, o transporte irregular, veículos sem condições de uso e a ausência de fiscalização. $O$ crescimento da frota veicular no estado de Goiás também contribui para o crescimento gradativo de acidentes de transito. 
Revista Científica do Corpo de Bombeiros Militar de Pernambuco

Seção 1 - Artigos Técnico Científicos

Artigo publicado no Vol.03 №06 - Edição de JAN a JUN 2017 - ISSN 2359-4829

Versão on-line disponível em: http://www.revistaflammae.com

As ocorrências com óleo diesel, gasolina e etanol envolveram o modal de transporte rodoviário, já para o GLP e para a amônia, os acidentes ocorreram no espaço de armazenamento.

A partir de 2009 os registros de ocorrências de acidentes com produtos químicos perigosos ganhou um aliado, a informatização do CBMGO, este sistema integrado de informação, de registro de dados possibilita a análise dos fatores relacionados às causas dos acidentes.

A obtenção de informações confiáveis e em tempo real dos acidentes, evidência as causas dos mesmos e contribui para o controle de forma eficiente, considerando-se que:

\subsection{Não Existem Atividades Com Produtos Químicos Com Risco Zero.}

Assim, a população como um todo e também o ambiente sempre estarão exposto aos riscos inerentes ao manejo de PP. Conclui-se com isto que são necessários investimentos públicos e privados no sentido de viabilizar a organização de um banco de dados com acesso irrestrito, alimentado por dados provenientes de instituições públicas, universidades e outros ramos da sociedade civil organizada. Os resultados integrados neste banco de dados possibilitará a organização de Planos de Contingência, cursos de treinamento, formação de profissionais especializados que atendam a necessidade do estado de Goiás bem como a gestão de recursos na prevenção, mitigação e tratamento de áreas contaminadas após acidentes com produtos químicos perigosos. 


\section{AGRADECIMENTOS}

Os autores agradecem ao CBMGO, Amônia Produtos Químicos Ltda, PUC Goiás, FAPEG

\section{REFERÊNCIAS BIBLIOGRÁFICAS}

BRASIL. Lei oㅜ 11.340, de 7 de agosto de 2006. Dispõe sobre a criação dos juizados de Violência Doméstica e Familiar contra a Mulher; altera o código de processo penal e a Lei de Execução Penal e dá outras providências, 2006.

AMONID. Amônia Produtos Químicos Ltda. Comunicação interna, Senador Canedo (GO), 2011.

ANP. Agencia Nacional do Petróleo, Gás Natural e Biocombustíveis. Anuário Estatístico Brasileiro do Petróleo, Gás Natural e Biocombustíveis. Rio de Janeiro: ANP, 2010.

BECKER, S. M.; PITT, R.; CLARK, S. Environmental Health, Public Safety, and Social Impacts Associated with Transportation Accidents Involving Hazardous Substances. Relatório publicado pela University Transportation Center for Alabama (UTCA), Tuscaloosa, Alabama, 2000.

CETESB. Companhia Ambiental do Estado de São Paulo. Relatório de emergências químicas, 2009.

CNT. Confederação Nacional de Transportes. Disponível em: <www.cnt.org.br>. Acesso em: 19 de setembro de 2014.

CONAB. Companhia Nacional de Abastecimento. Acompanhamento de safra brasileira: cana-de-açúcar, terceiro levantamento, 2011. Companhia Nacional de Abastecimento, Brasília: Conab 2011.

Acompanhamento de safra brasileira: cana-de-açúcar, primeiro levantamento, 2010. Companhia Nacional de Abastecimento, Brasília: Conab 2010. 
Revista Científica do Corpo de Bombeiros Militar de Pernambuco

Seção 1 - Artigos Técnico Científicos

Artigo publicado no Vol.03 №06 - Edição de JAN a JUN 2017 - ISSN 2359-4829

Versão on-line disponível em: http://www.revistaflammae.com

Acompanhamento da safra brasileira: Cana de açúcar. Safra 2009/2010. Terceiro levantamento, 2009.

Avaliação da safra de cana de açúcar 2007/2008. Terceiro levantamento de Goiás. SUREG-GO, 2007.

DETRAN. Departamento Estadual de Transito, Registro Nacional de Acidente e Estatística de Transito, no período de 2007-2010, 2010a.

Relatório de inclusão de veículos por tipo e combustível, no período de 2007-2010, $2010 \mathrm{~b}$.

FIEG/DEC. Federação das Indústrias do Estado de Goiás/Departamento Econômico. Estabelecimentos Empresariais em Goiás de 1990 a 2010, 2010.

FISPQ, Amônia Industrial, BR Distribuidora, Disponível em <http://www.br.com.br/wps/wcm/connect/ae308d8041f5a0d98d58ffdcb77f5b0c/f ispq-quim-amonia-industrial.pdf?MOD=AJPERES $>$. Acesso em 30 de março de 2016.

IAEA. RADIOLOGICAL ACCIDENT IN GOIÂNIA. Vienna: IAEA, 1988. 149 p. (STI/PUB/815).

IBAMA. Instituto Brasileiro do Meio Ambiente e Recursos Naturais Renováveis. Relatório de acidentes ambientais, 2010. Disponível em $<$ http://www.ibama.gov.br/phocadownload/emergencias_ambientais/relatrio_aci dentes_2010.pdf> Acesso em 30 de abril de 2014.

Relatório de acidentes ambientais, 2008. Disponível em $<$ http://www.ibama.gov.br/phocadownload/emergencias_ambientais/relatrio_aci dentes_2008.pdf>. Acesso em 30 de abril de 2014.

. Resolução CONAMA no 420, de 28 de dezembro 2009. Dispõe sobre critérios e valores orientadores de qualidade do solo quanto à presença de substâncias químicas e estabelece diretrizes para o gerenciamento ambiental de áreas contaminadas por essas substâncias em decorrência de atividades antrópicas. Diário Oficial [da] República Federativa do Brasil no 249, 2009.

- Perfil nacional de acidentes envolvendo produtos químicos perigosos. Disponível em: <http://www.mma.gov.br/segurancaquimica/emergencias-ambientais/estatisticas-de-acidentes>. Acesso em: 26 de fevereiro de 2016. 
MTE. Ministério do Trabalho e Emprego. Nota Técnica Número 03. Refrigeração industrial por amônia: riscos, segurança e auditoria fiscal. Brasil, 2004.

PEDRO, F. G. Acidente com transporte rodoviário de produtos perigosos: análise e aplicação de modelo conceitual georreferenciado para avaliação de risco ambiental no município de Campinas - SP. 2006. Dissertação (Mestrado) - Programa de Pós - Graduação em Engenharia Civil, Universidade Estadual de Campinas. 2006.

SEBRAE. Serviço Brasileiro de Apoio às Micro e Pequenas Empresas. Tecnologia da Informação, S/D.

SIAE/COB. Sistema Integrado de Atendimento a Emergência/Centro Estadual de Atendimento Operacional de Bombeiros. Banco de dados de acidente/incidente de produtos perigosos atendidos pelo Corpo de Bombeiros Militar do Estado de Goiás, período de 2007 a 2010.

SIAPI. Sistema Integrado de Análises de Projetos e Inspeções. Relatório de Inspeções, 2011.

TRANSPETRO, Petrobrás Transporte S. A. Relatório Interno da Supervisão do Terminal de Senador Canedo, 2011.

UNICA. União da Indústria de Cana de Açúcar. Relatório de Sustentabilidade, 2008. 